\title{
Neurocognitive Dysfunction in Head Injured Patients, Does It Reveal Various Outcomes in Both Sexes and Age-Groups?
}

\author{
Minoo Sharbafshaaer ${ }^{1 *}$, Sayan Bhattacharyya ${ }^{2}$ \\ ${ }^{1}$ Young Researchers and Elite Club, Zahedan Branch, Islamic Azad University, Zahedan, Iran \\ ${ }^{2}$ Department of microbiology, AllH\&PH, Kolkata -106, India
}

\begin{abstract}
Background: Traumatic brain injury (TBI) is one of the main causes of death and disability in both sex, young and old age group population in different countries. This study aimed to estimate effects of sex, age group and intensity level of TBI in neurocognitive dysfunction.

Methods: The study was done using the mini-mental state examination (MMSE) to estimate cognitive dysfunction that directed presence to the emergency department center with medical cares in the Zahedan city. Individuals were deliberated eligible if they were 18 years of age or older. This investigation covered 6-months.

Results: The sample study estimated 85 patients, $73 \%$ males with $27 \%$ females. The mean age patients reported 32.5 years (range 18-66 year) and SD (12.924) with 95\% CI. Two-way between groups analysis of variance test was used to assess the impacts of sex, age and level of TBI as measured by neurocognitive dysfunction. The interaction effect between sex, age group and level of TBI was statistically significant $F(0,85)=3.96, P=0.01$ however, the effect size was medium (partial eta squared $=0.54$ ).

Conclusion: This study supported research hypothesis that sex, age group and severity level of TBI show greater effect in neurocognitive dysfunction. In addition, the greatest amount of improvement in disability was observed among the male youngest group of survivors. These results advocate TBI survivors, especially older patients, may be candidates for neuroprotective therapies after TBI.

Keywords: Neurocognitive dysfunction; Traumatic brain injury (TBI); Sex; Age-group.
\end{abstract}

\author{
*Correspondence to \\ Minoo Sharbafshaaer, \\ Young Researchers and Elite \\ Club, Zahedan Branch, Islamic \\ Azad University, Zahedan, Iran. \\ Tel: 05433220501 . \\ Email: minoosharbaf@gmail. \\ com
}

Published online 20 December 2018

Citation: Sharbafshaaer M, Bhattacharyya S. Neurocognitive dysfunction in head injured patients, does it reveal various outcomes in both sexes and age-groups? Int Clin Neurosci J. 2018;5(4):121-125. doi: 10.15171/icnj.2018.24.

\section{Introduction}

Traumatic brain injury (TBI) is one of main causes of death and disability in many young and old population in many countries, ${ }^{1}$ with subsequent from TBI in neurological, neurocognitive, and behavioral impairments. ${ }^{2}$ Then it need unique aspects specific to the care of this patient population. ${ }^{3}$ TBI patients in young and old age are at high risk for neuro impairments in pragmatic language and social tasks. ${ }^{4}$ In addition, each individual who sustains a head injury is unique and therefore they will need individual attention, the deficits which result and the most appropriate rehabilitation goals for head-injured people have a commonality and can be applied generally. ${ }^{5}$

Neurocognitive dysfunction is the most result of TBI and main cause of disability, through intensity levels of TBI that indicated attention, processing speed, episodic memory, and executive function are most frequently influenced. ${ }^{6}$ Cognitive dysfunction is common outcomes in severity level of TBI patients. In particular, after the brain trauma, all patients underwent neurological examination including mini-mental state examination (MMSE), and Glasgow outcome scale (GOS). ${ }^{7}$ Study shows moderate to severe TBI patients reported neurocognitive deficits to include memory, language, executive functions, attention, and information processing speed deficiencies although neuropsychological alterations are present. ${ }^{8}$ Older adults without dementia and with prior TBI were more likely to report subjective memory impairment compared to those without TBI even after adjustment for demographics and medical comorbidities. ${ }^{9}$

However, there was statistically significant growth in the composite cognitive score and decline in functional connectivity in the right inferior frontal gyrus, with changes in the brain-behavior in the TBI patients. ${ }^{10}$ White matter disruption after brain injury shows cognitive dysfunction, then, white matter damaged related to particular patterns of neurocognitive deficit. ${ }^{11}$ The meantime, neurocognitive function was combined with outcomes, screening of cognitive function could be of importance in a clinical setting. ${ }^{12}$ 
Moreover, severity levels of TBI determine cognitive impairment. Levels of TBI contain; severe- moderate could release serious outcomes in cognitive function. Similar research declared moderate-to-severe TBI can cause varying degrees of cognitive control deficits positive relationship to injury severity correlated with self-reported cognitive control problems in everyday-life situations. ${ }^{13}$ TBI is a high-risk factor for cognitive function in older adults patients who got cognitive impairment. ${ }^{14}$ Intensity of TBI shows worse neurocognitive function, higher symptom severity and higher total number of symptoms, in general, TBI patient had cognitive deficit and outcomes symptom. ${ }^{15}$

In other words, sex and age group were important factors in TBI especially by these issues it would possible to set meaningful medical diagnosis and cares. As it known, TBI is a common yet devastating disease that affects people of all ages, predominantly the young and the elderly. ${ }^{16}$ TBI is a major public health problem, then both genders are affected, but knowledge about female TBI is little. Females had higher incidence of TBI and death than males in elderly age group. Furthermore, intensity of injuries reported more in female patients than male patients in middle and elder age groups. Generally, female TBI group differ significantly in the severity of injury and mortality. ${ }^{17}$ Age is a strong prognostic factor following TBI, with discrepancies defining the critical prognostic age threshold. ${ }^{18}$

In fact, importance of comprehensive neuropsychological assessments in each case of TBI in order to identify neurocognitive impaired could induce rehabilitation programs for severity degree of TBI. ${ }^{19}$ Therefore, the aims of this study were to estimate effects of sex, age group and intensity level of TBI in neurocognitive dysfunction to consider this three-factors to set more especial rehabilitation program for each factor in future.

\section{Materials and Methods \\ Participants and Procedures for Data Collection}

This study examined 85 patients with selecting sample availability random method. The investigation covered a 6-month period from March 2017 to December 2017. The patients had medical cares. Subjects were evaluated qualify if they were 18 years of age or older and had resistant traumatic brain injuries within 24 hours of presence to the emergency department center in the Zahedan city. Children and patients with previous orthopedic conditions were not eligible.

Data regarding the levels of severe brain injury and moderate TBI, data collected with two months after patients' discharge. Generally, the study was in 6 months.

\section{The Demographic Questionnaire}

First, patients convinced consent then they enrolled in this research and asked MMSE questions. It is a well-validated test for neurocognitive dysfunction for Iranian adults.
The cognitive instrument will make worth information for understanding the function of neurocognitive after TBI and manage TBI patients. ${ }^{20}$ Investigation indicated that MMSE purpose as well predictor of the disability rating scale in TBI patients. ${ }^{21}$ Validity for Persian version of MMSE in recognizing standard various abnormal cognition has been confirmed. The cut-off score for Iranian population with $98 \%$ and $100 \%$ sensitivity and specificity, respectively, the test usually takes about 10 minutes to complete the MMSE test in different ranges of cognitive domains, containing orientation, memory, language, attention and calculation, and ability to follow simple verbal and written instructions. ${ }^{22}$ In particular, MMSE employed as a short-form test in clinics and research implement for diagnosing the neurocognitive dysfunction and dementia,. ${ }^{23}$ Scores of 25-30 out of 30 are measured normal; the National Institute for Health and Care Excellence (NICE) classifies reported 21-24 as mild, $10-20$ as moderate and $<10$ as severe impairment. ${ }^{24}$

\section{Data Analysis}

Evaluated data have been done with SPSS, version 25.0. Data reported as frequencies mean. Parametric tests used, thus, the two-way ANOVA test was assessed effect of sex, age and level neurocognitive dysfunction. Variables found to be significant $(P<0.05)$ with a cut-off for rejection of variables from the model of $P=0.10$.

\section{Results}

The sample study estimated 85 patients, $73 \%$ males with $27 \%$ females. The mean age patients reported 32.5 years (range 18-66 year) and SD (12.924) with 95\% CI. Following research injury was reported when the patients presented to the emergency department (ED): $17 \%$, Severe; Moderate, $83 \%$; and Mild TBI was not analyzed in this research.

Two-way between groups analysis of variance test was used to assess the effects of sex, age and level of TBI as measured by neurocognitive dysfunction. Participants were divided into five groups according to their age (group 1: 18-29 years; group 2: 30-39 years; group 3: 4049 years; group 4: 50-64 years; group 5: $\geq 65$ years ). The interaction effect between sex, age group and level of TBI was statistically significant $F(0,85)=3.96, P=0.01$. However, the effect size was medium (partial eta squared $=0.54)$ (Table 1$)$.

Post-hoc comparisons using the LSD test indicated that the mean score for the 18-29 years age group $(\mathrm{M}=$ $14.11, \mathrm{SD}=6.17), 30-39$ years age group $(\mathrm{M}=20, \mathrm{SD}=$

Table 1. Interaction Effect Between Sex, Age Group and Level of TBI With Neurocognitive Dysfunction

\begin{tabular}{lcccc}
\hline & $\boldsymbol{d f}$ & $\boldsymbol{F}$ & $\boldsymbol{P}$ & Partial Eta Square \\
\hline Sex* age group* level of TBI & 0 & 3.96 & 0.01 & 0.5 \\
\hline
\end{tabular}

Dependent variable: MMSE. 
$5.2)$, and 40-49 years age group $(\mathrm{M}=22.81, \mathrm{SD}=3.34)$ were significantly different in both sex and levels of TBI. The 50-64 years age group $(\mathrm{M}=20.66, \mathrm{SD}=3.44)$ and $\geq 65$ years age group $(\mathrm{M}=18.44, \mathrm{SD}=4.63)$ did not differ significantly from either of the other groups. The main effect for TBI's level, $F(1,85)=18, P=0.001$ was reach statistical significant while main effect for sex, $F(1,85)=$ $1.9, P=0.17$ did not reach statistical significant.

The males in 18-29 age group years show worse neurocognitive function while 50-64 years was better cognitive score. In contrast, females by increasing age indicated lower cognitive function (Figure 1).

\section{Discussion}

This investigation showed there is a direct interaction between intensity of TBI (severe-moderate) with neurocognitive dysfunction, then mild-to-severe TBI leads various levels of neurocognitive dysfunction, that it had a negative effect on long-term functional outcomes. Recently published studies in levels of TBI reported TBI to demonstrate long-standing cognitive dysfunction. ${ }^{25}$

Also, neurocognitive dysfunction had dynamic changes in the thalamus and white matter (WM) as well as cognitive dysfunction during the follow-up period. ${ }^{26}$ Similar study indicated, there are differences between moderate and severe TBI patients in neurocognitive deficits with problems in executive dysfunction, attention, and their improvement over time. ${ }^{27}$ In contrast, researchers contend that TBI influenced cognition in moderate as well as severe cases, so cognitive impairment could refer future disability in severe and moderate TBI patients. ${ }^{28}$

Sex different for TBI are an important variable to determine cognitive dysfunction; indeed both sex of TBI patients indicated a variable rate of neurocognitive dysfunction. Other research indicated Female patient was not an independent risk factor for in-hospital mortality after TBI. ${ }^{29}$ In contrast, the study results show that female TBI injured vary significantly in the severity of injury and mortality. ${ }^{30}$ While similar result observed the most common recognized risk factors are sex, males are nearly three times more likely to suffer a TBI than females. ${ }^{31}$

Neurocognitive dysfunction related to the age-groups which it can be predictable by age. Particularly, age-group strongly associated with the neurocognitive severity function. Furthermore, research declared age-adjusted is major contributing factor, it might be a reduced number of traffic-related head trauma. ${ }^{32}$ Even though in patients with TBI, age demonstrates independent association with unfavorable cognitive dysfunction outcomes at 6 months. ${ }^{33}$ Investigation indicated These results were consistent with reports of TBI as a significant risk factor for cognitive decline in older adults, and TBI is associated with an earlier patients. ${ }^{34}$ While After maximum spontaneous recovery from TBI, poorer cognitive functioning appears to be associated with both older age at the time of injury and increased time post injury. ${ }^{35}$

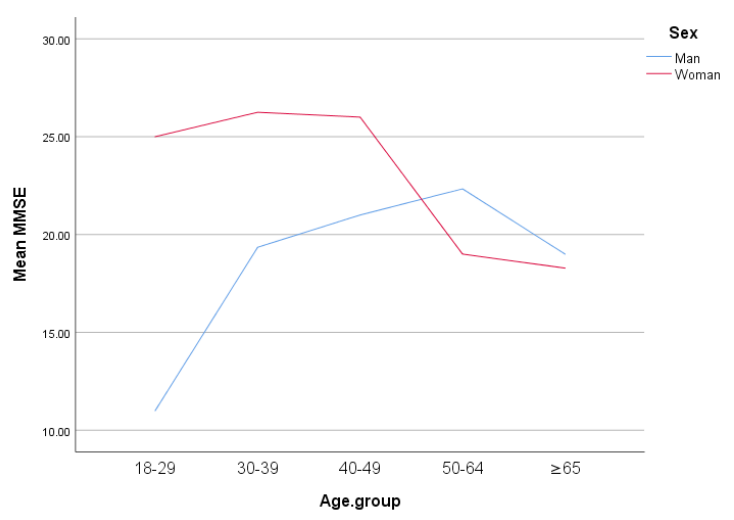

Figure 1. Neurocognitive Dysfunction by Sex and Age Group.

Our study suggests that sex, age-group and intensity of TBI are valuable variables to predict neurocognitive dysfunction in head injured patients also, TBI effects most in neurocognitive functions. Gender, age-group and intensity level of TBI (sever-moderate) play the potential compensatory role to indicate the severity of cognitive impairment. While another study declared moderateto-severe TBI survivors is associated with functional changes in the brain with cognitive deficit. ${ }^{36}$ Although this study provides insight into gender differences on outcomes after TBI, there are significant differences between problems reported by men compared to women. This insight may facilitate health service planners and clinicians when developing programs for individuals with brain injury. ${ }^{37}$ The effect of gender and age could be stronger in some countries than others. It reflects the necessity of incorporating geographic patterns as well as demographic features of patients while developing treatments and designing clinical trials was needed..$^{38}$ TBI differences in outcomes need to be assessed for potential moderating effects of sex and age. Results have important implications for more tailored injury prevention efforts. ${ }^{39}$

However, there are different cognitive rehabilitation methods and combinations in various neurocognitive deficits. ${ }^{40}$ Also, Gender, age-group and intensity level of TBI should consider for the future rehabilitation program.

Although the present study was accurately prepared, there were statistically significant differences with sex, age-group and intensity of TBI, as estimated by of neurocognitive dysfunction. It means sex, age-group and level of TBI in patients are remarkable variables on score achievement in all dimensions of cognitive impairment. For example, the results of this study would have confirmed sex, age-group and intensity level of TBI play a serious role in neurocognitive deficit then it required direct attention for the rehabilitation program. Also, the present study had the limitation as the duration of this study was nearly short (8 months), it seems worthwhile that the long-term impacts of the sex, age-group and intensity level of TBI on neurocognitive impairment investigated in larger groups of TBI patients. 


\section{Conclusion}

This study supported research hypothesis that sex, age group and severity level of TBI show greater effect in neurocognitive dysfunction. In addition, the greatest amount of improvement in disability was observed among the male youngest group of survivors. These results advocate TBI survivors, especially older patients, may be candidates for neuroprotective therapies after TBI.

\section{Conflict of Interest Disclosures}

The authors declare that they have no conflict of interests.

\section{Ethical Statement}

The Zahedan University of Medical Sciences approved this study. Patients were asked to sign the Free and Informed Consent Form, after due explaining concern $\neg$ in the study and before data collection.

\section{Acknowledgment}

We would appreciate patients work in partnership to provide expert clinical data during the investigation and members of the Khatam Hospital Emergency Department.

\section{References}

1. Barlow KM. Traumatic brain injury. Handb Clin Neurol. 2013;112:891-904. doi: 10.1016/B978-0-444-529107.00011-8.

2. Giza CC. Traumatic brain injury. In: Lisak RP, Truong DD, Carroll WM, Bhidayasiri R, eds. International Neurology. Wiley; 2016. doi:10.1002/9781118777329.ch171

3. Abou El Fadl MH, O'Phelan KH. Management of Traumatic Brain Injury. Neurol Clin. 2017;35(4):641-653. doi: 10.1016/j. ncl.2017.06.003.

4. Turkstra L, Politis AM. Traumatic Brain Injury. In: Cummings L, ed. Research in Clinical Pragmatics. Springer; 2017:291-322.

5. Birkhead S. Post冈traumatic brain injury. In: Crouch R, Alers V, eds. Occupational Therapy in Psychiatry and Mental Health. 5th ed. Wiley; 2014:356-367.

6. Wortzel HS, Arciniegas DB. Treatment of post-traumatic cognitive impairments. Curr Treat Options Neurol. 2012;14(5):493-508.

7. Alemam Al, Mohamad HA, Alhadad AA. Memory and attention impairment after traumatic brain injury. Egyptian Journal of Neurology, Psychiatry and Neurosurgery. 2013;50(2):143-148.

8. Miotto EC, Cinalli FZ, Serrao VT, Benute GG, Lucia MC, Scaff M. Cognitive deficits in patients with mild to moderate traumatic brain injury. Arq Neuropsiquiatr. 2010;68(6):862-8.

9. Gardner RC, Langa KM, Yaffe K. Subjective and objective cognitive function among older adults with a history of traumatic brain injury: A population-based cohort study. PLoS Med. 2017;14(3):e1002246. doi: 10.1371/journal. pmed.1002246.

10. Porter S, Torres IJ, Panenka W, Rajwani Z, Fawcett D, Hyder A, et al. Changes in brain-behavior relationships following a 3-month pilot cognitive intervention program for adults with traumatic brain injury. Heliyon. 2017; 3(8): e00373. doi: 10.1016/j.heliyon.2017.e00373.

11. Kinnunen KM, Greenwood R, Powell JH, Leech R, Hawkins $\mathrm{PC}$, Bonnelle $\mathrm{V}$, et al. White matter damage and cognitive impairment after traumatic brain injury. Brain. 2011;134(Pt 2):449-63. doi: 10.1093/brain/awq347.

12. Stenberg M, Godbolt AK, Nygren De Boussard C, Levi R, Stålnacke BM. Cognitive impairment after severe traumatic brain injury, clinical course and impact on outcome: a
Swedish-Icelandic study. Behav Neurol. 2015;(3):1-12. doi: 10.1155/2015/680308.

13. Olsen A, Brunner JF, Indredavik Evensen KN, Finnanger TG, Vik A, Skandsen T, et al. Altered cognitive control activations after moderate-to-severe traumatic brain injury and their relationship to injury severity and everyday-life function. Cereb Cortex. 2015; 25(8): 2170-80. doi:10.1093/cercor/ bhu023.

14. Li W, Risacher SL, McAllister TW, Saykin AJ. Traumatic brain injury and age at onset of cognitive impairment in older adults. J Neurol. 2016;263(7):1280-5. doi: 10.1007/s00415016-8093-4.

15. Bloom BM, Kinsella K, Pott J, Patel HC, Harris T, Lecky F, et al. Short-term neurocognitive and symptomatic outcomes following mild traumatic brain injury: A prospective multicenter observational cohort study. Brain Inj. 2017;31(3):304311. doi: 10.1080/02699052.2016.1256501.

16. Tate R, Simpson G, McRae PH. Traumatic Brain Injury. In: Escorpizo R, Brage S, Homa D, Stucki G, eds. Handbook of Vocational Rehabilitation and Disability Evaluation. Springer; 2015. doi: 10.1007/978-3-319-08825-9 12

17. Moyer MT, Kumar MA. Traumatic Brain Injury. In: White JL, Sheth KN, eds. Neurocritical Care for the Advanced Practice Clinician. Springer; 2018. doi: 10.1007/978-3-319-48669710.

18. Munivenkatappa A, Agrawal A, Shukla DP, Kumaraswamy D, Indira Devi B. Traumatic brain injury: Does gender influence outcomes? Int J Crit Illn Inj Sci. 2016;6(2):70-73.

19. Miotto EC, Cinalli FZ, Serrao VT, Benute GG, Lucia MC, Scaff M. Cognitive deficits in patients with mild to moderate traumatic brain injury. Arq Neuropsiquiatr. 2010;68(6):862-8.

20. Wang ML, Li WB. Cognitive impairment after traumatic brain injury: the role of MRI and possible pathological basis. J Neurol Sci. 2016;15(370):244-250. doi: 10.1016/j.jns.2016.09.049.

21. de Guise E, Leblanc J, Champoux MC, Couturier C, Alturki AY, Lamoureux J, et al. The mini-mental state examination and the Montreal Cognitive Assessment after traumatic brain injury: an early predictive study. Brain Inj. 2013;27(12):1428-34. doi: 10.3109/02699052.2013.835867.

22. Ansari NN, Naghdi S, Hasson S, Valizadeh L, Jalaie S. Validation of a mini-mental state examination (MMSE) for the Persian population: a pilot study. Appl Neuropsychol. 2010;17:190-195.doi: 10.1080/09084282.2010.499773.

23. de Guise E, Leblanc J, Champoux MC, Couturier C, Alturki AY, Lamoureux J, et al. The mini-mental state examination and the Montreal Cognitive Assessment after traumatic brain injury: an early predictive study. Brain Inj. 2013;27(12):1428-34. doi: 10.3109/02699052.2013.835867.

24. Willacy H. Mini Mental State Examination. Lancaster: Lancaster University, Department: Lancaster Medical School; [updated 2017 February 6]. Available from: https://patient. info/doctor/mini-mental-state-examination-mmse.

25. Mclnnes K, Friesen CL, MacKenzie DE, Westwood DA, Boe SG. Mild Traumatic Brain Injury (mTBI) and chronic cognitive impairment: A scoping review. PLoS One. 2017;12(4):e0174847. doi: 10.1371/journal.pone.0174847.

26. Grossman EJ, Jensen JH, Babb JS, Chen Q, Tabesh A, Fieremans $\mathrm{E}$, et al. Cognitive impairment in mild traumatic brain injury: a longitudinal diffusional kurtosis and perfusion imaging study. AJNR Am J Neuroradiol. 2013;34(5):951-7, S13. doi: 10.3174/ajnr.A3358.

27. Finnanger TG, Skandsen T, Andersson S, Lydersen S, Vik A, Indredavik M. Differentiated patterns of cognitive impairment 12 months after severe and moderate traumatic brain injury. Brain Inj. 2013;27(13-14):1606-16. doi: 10.3109/02699052.2013.831127.

28. Skandsen T, Finnanger TG, Andersson S, Lydersen S, Brunner JF, Vik A. Cognitive impairment 3 months after moderate and severe traumatic brain injury: a prospective follow-up 
study. Arch Phys Med Rehabil. 2010;91(12):1904-13. doi: 10.1016/j.apmr.2010.08.021.

29. Leitgeb J, Mauritz W, Brazinova A, Janciak I, Majdan M, Wilbacher I, et al. Effects of gender on outcomes after traumatic brain injury. J Trauma. 2011;71(6):1620-6. doi: 10.1097/TA.0b013e318226ea0e.

30. Munivenkatappa A, Agrawal A, Shukla DP, Kumaraswamy D, Indira Devi B. Traumatic brain injury: Does gender influence outcomes?. Int J Crit Illn Inj Sci. 2016;6(2):70-3. doi: 10.4103/2229-5151.183024.

31. Gardner AJ, Zafonte R. Neuroepidemiology of traumatic brain injury. Handb Clin Neurol. 2016;138:207-23. doi: 10.1016/ B978-0-12-802973-2.00012-4.

32. Chen C, Peng J, Sribnick EA, Zhu M, Xiang H. Trend of ageadjusted rates of pediatric traumatic brain injury in U.S. emergency departments from 2006 to 2013. Int J Environ Res Public Health. 2018 5;15(6). doi: 10.3390/ijerph15061171.

33. Dhandapani S, Manju D, Sharma B, Mahapatra A. Prognostic significance of age in traumatic brain injury. J Neurosci Rural Pract. 2012;3(2):131-5. doi: 10.4103/0976-3147.98208.

34. Li W, Risacher SL, McAllister TW, Saykin AJ. Traumatic brain injury and age at onset of cognitive impairment in older adults. J Neurol. 2016;263(7):1280-5. doi: 10.1007/s00415016-8093-4.

35. Senathi-Raja D, Ponsford J, Schönberger M. Impact of age on long-term cognitive function after traumatic brain injury. Neuropsychology. 2010;24(3):336-344. doi: 10.1037/ a0018239.

36. Olsen A. Cognitive Control Function and Moderate-to-Severe Traumatic Brain Injury: Functional and Structural Brain Correlates [dissertation]. Trondheim: Norwegian University of Science and Technology; 2014.

37. Colantonio A, Harris JE, Ratcliff G, Chase S, Ellis K. Gender differences in self reported long term outcomes following moderate to severe traumatic brain injury. BMC Neurol. 2010;10:102. doi: 10.1186/1471-2377-10-102.

38. Kishore Biswas R, Kabir E, King R. Effect of sex and age on traumatic brain injury: a geographical comparative study. Arch Public Health. 2017;75: 43. doi: 10.1186/s13690-0170211-y.

39. Ilie G, Adlaf EM, Mann RE, Boak A, Hamilton $H$, Asbridge M. The moderating effects of sex and age on the association between traumatic brain injury and harmful psychological correlates among adolescents. PLoS One. 2014;30;9(9):e108167. doi: 10.1371/journal.pone.0108167.

40. Barman A, Chatterjee A, Bhide R. Cognitive impairment and rehabilitation strategies after traumatic brain injury. Indian J Psychol Med. 2016;38(3):172-81. doi: 10.4103/02537176.183086. 